\title{
PERSPEKTIF MASYARAKAT DIGITAL TERHADAP DAKWAH ONLINE DI INSTAGRAM DI TENGAH PANDEMI COVID-19
}

\author{
Lukman Al-Hakim \\ UIN Syarif Hidayatullah Jakarta \\ lukman88united@gmail.com
}

\begin{abstract}
Abstrak
Tujuan dari penelitian ini adalah: mengklasifikasi para da'i dari jumlah follower tertinggi hingga follower terendah dan melihat perspektif masyarakat digital tehadap dakwah di media sosial Instagram para da'i ditengah pandemi covid-19. Penulis menggunakan teori Uses and Gratifications Wilbur Schramm 1970, yaitu khalayak dilihat sebagai individu aktif dan memiliki tujuan, bertanggung jawab dalam pemilihan media yang akan mereka gunakan untuk memenuhi kebutuhan dan kepuasan mereka. Terdapat tiga karakteristik dari teori ini yaitu: Interactivity, bermakna terjadi komunikasi dua arah baik da'i maupun mad'u. Demassification, bermakna kontrol sistem komunikasi bergeser dari da'i ke mad'u yaitu kebebasan mad'u menerima pesan dakwah yang disampaikan da'i sesuai dengan kebutuhan mereka. Asynchroneity, bermakna kemampuan untuk menentukan waktu pengiriman dan penerimaan pesan pada waktu yang ditentukan dan aspek interpersonal seperti mengirim, menerima dan menyimpan pesan dakwah online sesuai kebutuhan. Metode yang digunakan dalam penelitian ini adalah studi kasus, penulis berupaya menelaah data mengenai subjek yang diteliti yaitu akun Instagram para da'i dengan observasi, wawancara follower, dokumentasi dan kepustakaan untuk menguraikan suatu kasus secara terinci. Hasil dari penelitian ini, yaitu dakwah online menggunakan Instagram ditengah pandemi covid-19 cukup efektif. Hal ini berdasarkan tingginya jumlah follower di laman media sosial Instagram para da'i serta respon positif yang diberikan follower pada kajian online ini.
\end{abstract}

Kata Kunci: Dakwah Online, Instagram, Follower dan Covid-19. Permalink/DOI: http://doi.org/10.15408/jsj.v3i2.22985

\section{A. PENDAHULUAN}

Mewabahnya covid-19 yang belum berakhir sejak 2019 hingga saat ini berdampak negatif pada berbagai aspek kehidupan mulai dari pendidikan, sosialekonomi, sampai pada kegiatan kerohanian dan keagamaan salah satunya kajian dakwah Islam. Kegiatan dakwah Islam yang biasa dilakukan secara offline di berbagai tempat seperti masjid atau majlismajlis ilmu saat kondisi normal, kini belum bisa dilakukan sepenuhnya karena penerapan protokol kesehatan yang begitu ketat. Akibatnya, kegiatan dakwah offline yang rutin dijadwalkan di beberapa tempat

1 Strategi Dakwah et al., "Dawatuna : Journal of Communication and Islamic saat ini masih vakum, diliburkan dan diganti dengan online. ${ }^{1}$

Upaya kegiatan dakwah Islam ini harus tetap berjalan lancar sebagaimana mestinya meskipun dengan jarak jauh (online). Sebagaimana diketahui visi dan misinya dakwah Islam sendiri mengandung pengertian sebagai seruan untuk berbuat baik dalam bentuk lisan, tulisan, sikap dan tingkah laku dalam upaya mempengaruhi orang lain agar timbul dalam dirinya suatu kesadaran,

Broadcasting Peran Instagram Sebagai Media Dakwah Pada Masa Pandemi :" 2 (2022): 81-97. 
pemahaman, sikap penghayatan serta pengamalan terhadap ajaran Islam. ${ }^{2}$

Sedikit menoleh kebelakang bahwa perkembangan media online telah dibayangkan oleh Marshall McLuhan sejak awal 1960-an, seperti lahirnya pasar online, kampanye online, hingga kehidupan keagamaan yang menggunakan internet dalam berbagai fungsi dan karakternya. ${ }^{3}$ Menunjukkan bahwa media online merupakan sumber yang menghadirkan agama dalam berbagai dimensinya, walaupun tidak jarang terjadi "penolakan" penggunaan media online bagi tujuan agama karena dianggap mengandung ancaman norma-norma sosial agama dan otoritas pemimpin agama.

Penggunaan media online sebagai sarana dakwah Islam mulai menjadi alternative dalam berdakwah apalagi di masa pandemi saat ini. Selain itu dalam menyampaikan materi-materi dakwah seorang da'i telah memiliki beberapa akun alternatif di media sosial seperti; Instagram, YouTube, Facebook, Twitter, Line, WhatsApp, Weblog, dan lain sebagainya. ${ }^{4}$ Sejak 2020-2021 Instagram memasuki urutan ketiga sebagai media sosial paling populer di Indonesia dibawah Youtube dan WhatsApp, seperti pada gambar dibawah ini:

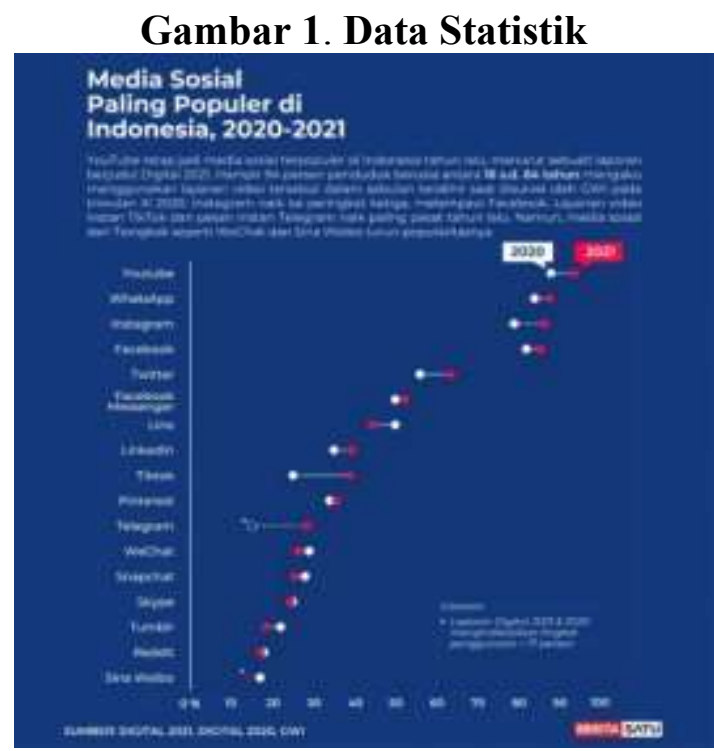

Sumber: beritasatu.com

Dari data statisik diatas terbukti masih tingginya pengguna Instagram khususnya di Indonesia dimasa pandemi ini. Pencapaiannya meningkat sejak 2020 hingga januari 2021 melampaui Facebook dan Twitter. Sehingga penulis memilih akun Instagram para da'i sebagai sumber

2 H. M. Arifin, Psikologi Dakwah Suatu Pengantar (Cetakan Pertama). Jakarta: Bumi Aksara, 1991: 6

3 Wahyudi Marhaen Pratopo and Nasrullah Kusajibrata, "Konvergensi Di Ruang Redaksi Pada Kelompok Media Tempo," Jurnal Studi data penelitian penulis berdasarkan tingginya jumlah follower mereka.

Instagram adalah sebuah aplikasi dari handphone yang khusus untuk media sosial yang merupakan salah satu dari media digital yang mempunyai fungsi yang hampir sama dengan media sosial lainnya seperti Twitter, namun perbedaannya

\footnotetext{
Komunikasi (Indonesian Journal of Communications Studies) 2, no. 1 (2018): 126-142.

${ }^{4}$ Fadly Usman, "Efektivitas Penggunaan Media Online Sebagai Sarana Dakwah," Jurnal Ekonomi dan Dakwah Islam (Al-Tsiqoh) 1, no. 1 (2016): 18.
} 
terletak pada pengambilan foto dan video dalam bentuk atau tempat untuk berbagi informasi terhadap penggunanya. Instagram juga dapat memberikan inspirasi bagi penggunanya dan dapat meningkatkan

\section{Gambar 2. Logo Instagram dan Perubahannya}

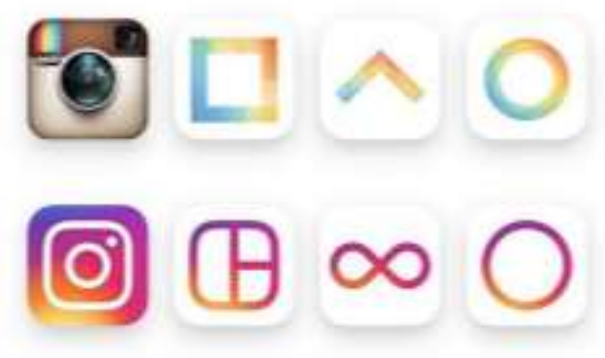

Sumber: liputan6.com

Instagram akan memfasilitasi para pengguna akun sosial untuk melakukan apa saja di internet seperti halnya dakwah online ini. Hanya dengan berbekal kamera dan kuota serta jaringan internet yang stabil untuk dapat meng-upload rekaman gambar atau video ceramah yang dimiliki para da'i. Mereka dengan mudah memberikan tausiyahnya kapan pun dan dimanapun berada dan masyarakat diseluruh dunia dapat dengan mudah mendengarkan tausiyahnya. Hal ini semakin menguatkan pendapat bahwa siapapun dapat berbuat apa saja dengan teknologi internet. Setiap aktivitas seseorang da'i lewat media sosial Instagram akan digerakkan melalui serangkaian teknologi digital. Teknologi ini dioperasikan dengan menekan beberapa digit (angka) yang disusun dengan berbagai urutan. Relasi yang terbangun di antara individu adalah relasi pertukaran digital, seseorang hanya melakukan serangkaian transaksi atau interaksi melalui simbol-simbol digital.

5 Bambang Dwi Atmoko, Instagram Handbook, (Jakarta: Media Kita, 2012):10 kreatifitas, karena Instagram mempunyai fitur yang dapat membuat foto dan video menjadi lebih indah, lebih artistik dan menjadi lebih bagus. ${ }^{5}$

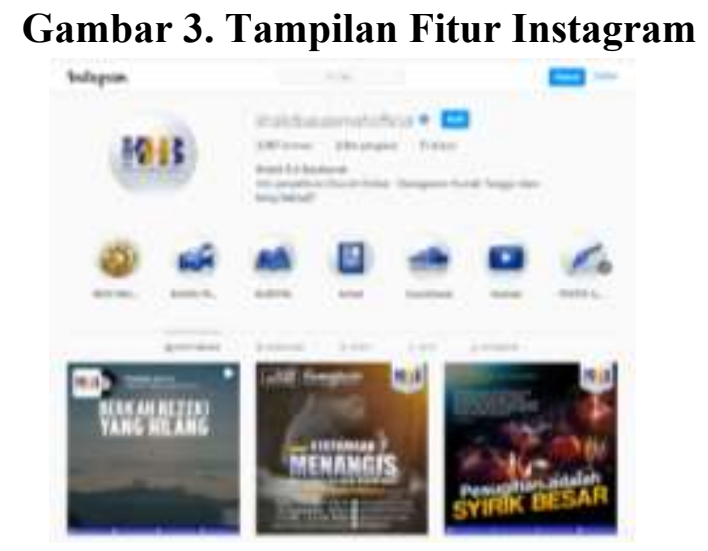

Sumber: khalidbasalamahofficial

Perkembangan teknologi yang pesat akan modernisasi dan pembaharuan teknologi seperti hadirnya smartphone sangat berpengaruh bagi masyarakat digital seiring perkembangan zaman. Arti Smartphone menjadi sangat penting, suatu hal yang tidak bisa lepas dari diri seorang individu utamanya bagi masyarakat digital yang sebagian besar waktunya untuk memainkan Smartphone. Sudah bukan rahasia umum lagi Smartphone berbasis android ini telah menjadikan arus informasi tidak lagi hanya lewat televisi, radio, buku ataupun majalah. Keberadaan android yang semakin luas penyebarannya hingga ke berbagai pelosok, ditambah lagi dengan terus ditingkatkannya akses jaringan teknologi informasi menjadikan smartphone sebagai mesin yang selalu ada digenggaman tangan. Informasi apapun yang ingin didapat sudah tidak lagi memerlukan waktu yang cukup lama untuk diakses seperti halnya dakwah online dimasa pandemi ini. Para pengguna smartphone menjadi sasaran utama para 
da' $i$ agar tetap bisa memanfaatkan smartphonenya untuk terus mengikuti kajian secara daring.

Terdapat beberapa penelitian terdahulu yang relevan dengan penelitian ini. Farhan Ar'Rayyan (2021) berjudul: "Peran Instagram sebagai Media Dakwah pada Masa Pandemi: Strategi Dakwah Akun @Penuntutilmu.Bogor”. Penelitian ini ingin melihat peran media sosial Instagram sebagai media dakwah pada masa pandemi serta bagaimana strategi dakwah yang dilakukan komunitas tersebut. Hasil yang diperoleh dalam penelitian ini, media sosial Instagram sebagai media dakwah pada masa pandemi memiliki berbagai peran dengan memanfaatkan fitur-fitur yang ada didalamnya, selain itu Instagram berperan sebagai media komunikasi, media berbagi, media amal, media promosi dan media penyimpanan. Untuk strategi dakwahnya dibagi menjadi 3 tahapan yaitu tahap perencanaan, tahap penerapan, dan tahap penilaian, adapun strategi dakwah yang digunakan yaitu dakwah bil lisan, dakwah bil qolam dan dakwah bil hal.

Diajeng Laily Hidayati (2020) berjudul: "Dakwah di Tengah Pandemi (Studi terhadap Respons Dai di Media Sosial)". Penelitian ini bertujuan untuk mendeskripsikan respons da'i di media sosial terhadap penyebaran wabah Covid19. Hasil penelitian menunjukkan bahwa terdapat tiga respons yang muncul dari para dai, yaitu respons kognitif dengan menyampaikan informasi tentang covid-19 dari sudut pandang jasmaniah seperti menjaga kesehatan, kebersihan, himbauan untuk menaati pemerintah, dan penjelasan rohaniah seperti anjuran untuk tetap bersyukur dan bertawakal kepada Allah SWT di tengah kondisi wabah Covid-19.

\section{B. METODE PENELITAN}

Penulisan ini menggunakan pendekatan kualitatif, yaitu penulisan yang berupaya untuk menghimpun, mengolah, dan
Respons afektif tampak melalui anjuran untuk berempati, berpikir positif, dan tidak panik. Selanjutnya, respons konatif/behavioral berupa perilaku nyata dengan menggelar pengajian secara daring dan menunjukkan perilaku pencegahan penyebaran serta penanggulangan wabah covid-19 seperti menggunakan masker, melakukan penyemprotan, dan memberikan bantuan terhadap masyarakat yang terkena dampak Covid-19.

Ahmad Fauzi (2020) berjudul: "Problematika Dakwah Ditengah Pandemi Covid-19". Peneltian ini melihat peran media sosial di dalamnya. Sampai membuat pengaruh yang bersifat masif dalam kehidupan seseorang baik bagi masyarakat khususnya kalangan remaja, media sosial sudah menjadi candu yang membuat penggunanya tiada hari tanpa membuka media sosial. Lantas, Islam adalah agama yang "rahmatan lil alamin". Sehingga Islam harus disebarluaskan kepada seluruh umat.

Tiga penelitian yang menjadi tinjuan pustaka penulis diatas cenderung menunjukkan pemanfaatan fitur-fitur yang ada dikolom Instagram, respons yang muncul dari para da'i yaitu: respons kognitif, respons afektif, dan respons konatif/behavioral serta pengaruh dakwah online yang bersifat masif dalam kehidupan seseorang baik bagi masyarakat khususnya kalangan remaja. Oleh sebab itu, penelitian ini mengambil posisi berbeda dari tiga penelitian sebelumnya, yakni fokus pada klasifikasi jumlah follower tertinggi sampai terendah yang penulis ambil dari Instagram para da'i dengan melihat respon dan tanggapan follower mereka selama mengikuti kajian online.

menganalisa data secara detail dan mendalam. Penulisan kualitatif melihat subjek dan objek penulisan berdasarkan 
kenyataan yang ada di lapangan dan berusaha mencari makna yang terkandung di dalamnya. Jenis penulisan yang digunakan adalah penulisan deskriptif yaitu penulisan yang berusaha untuk mendeskripsikan suatu gejala, peristwa ataupun kejadian yang sekarang terjadi. Pendekatan kualitatif merupakan suatu pendekatan yang menghasilkan suatu data deskriptif berupa kata-kata tertulis atau lisan dari orang atau perilaku yang dapat diamati. $^{6}$

Subjek dari penelitian ini adalah media sosial Instagram para da'i sebagai alat untuk menyampaikan pesan dakwahnya. Objek peneltian ini adalah follower akun Instagram para da'i yang konsisten mengikuti kajian online kapanpun dan dimanapun mereka berada.

Pendekatan yang dipergunakan dalam penulisan ini adalah pendekatan studi kasus yaitu suatu serangkaian kegiatan ilmiah yang dilakukan secara intensif, terinci dan mendalam tentang suatu program, peristiwa, dan aktivitas, baik pada tingkat perorangan, sekelompok orang, lembaga, atau organisasi untuk memperoleh pengetahuan mendalam tentang peristiwa tersebut. Atau dengan kata lain merupakan suatu inkuiri empiris yang menyelidiki fenomena di dalam konteks kehidupan nyata bilamana batasbatas antara fenomena dan konteks tidak tampak dengan tegas dan dimana multi sumber bukti dimanfaatkan. ${ }^{7}$

Alasan penulis menggunakan pendekatan studi kasus dalam penulisan ini didasarkan kepada beberapa faktor seperti:

1. Kasus yang diangkat menarik untuk diteliti. Hal tersebut bisa dilihat dari fokus penelitian, yaitu bagaimana tingginya antusiasme masyarakat digital mengikuti kajian online selama

6 Lexy J, Moleong, Metode Penulisan Kualitatif, Bandung: Remaja Karya, (1989): 3.

${ }^{7}$ Robert K. Yin, Qualitative Research from Start to Finish. The Guilford: New York London (2011): 277. masa pandemi dengan menjadi follower di laman media sosial Instagram para da'i.

2. Penelitian ini menghendaki adanya penyingkapan yakni adanya penggalian yang mendalam mengenai konsistensi dakwah online di era pandemi.

Prosedur pengumpulan data yang digunakan dalam penulisan ini adalah sebagai berikut:

1. Observasi

Yaitu pemilihan, pengubahan, pencatatan dan pengkodean serangkaian perilaku dan suasana yang berkenaan dengan organisasi, sesuai dengan tujuantujuan empiris. Observasi berguna untuk menjelaskan dan merinci gejala-gejala yang terjadi. ${ }^{8}$ Observasi ialah teknik pengumpulan data dengan mengadakan peninjauan secara langsung di laman media sosial Instagram para da'i yang menjadi sarana dan wadah untuk menyampaikan pesan dakwahnya. Untuk mendapatkan data yang dibutuhkan penulis dalam penulisan ini, penulis mengamati segala sesuatu yang berhubungan dengan jumlah follower Instagram para da'i, dengan mengkalisifikasi jumlah follower berdasarkan urutannya mulai dari yang paling tinggi hingga terendah dan dari hasil observasi tersebut dijadikan sebagai data primer penulis

\section{Wawancara}

Wawancara yang digunakan oleh penulis dalam penulisan ini adalah wawancara terbuka (Opended interview). Wawancara adalah bentuk komunikasi antara dua orang, melibatkan seseorang yang ingin memperoleh informasi dari seseorang dengan mengajukan pertanyaanpertanyaan berdasarkan tujuan tertentu. ${ }^{9}$ Pihak yang menjadi narasumber yaitu

8 John Cresswell, Penulisan kualitatif dan desain riset: Memilih di antara 5 Pendekatan. Yogyakarta: Pustaka Pelajar. (2015): 205.

9 Deddy Mulyana, Analisis Framing. Jogjakarta: LKiS. (2002). 71 
follower akun Instgaram para da'i dan data yang diperoleh dari hasil wawancara tersebut dijadikan sebagai data sekunder, yaitu data yang diperoleh dari informan melalui wawancara yang dilakukan oleh penulis.

3. Dokumentasi

Yaitu menggali informasi atau pengetahuan yang ada hubungannya

\section{LANDASAN TEORI}

Teori uses and gratifications (kebutuhan dan kepuasan) ${ }^{10}$ lahir untuk mengkritik teori bullet yang dikembangkan oleh Wilbur Schramm pada tahun 1930-an. Awalnya, teori bullet berpendapat bahwa pengguna media dianggap sebagai pengguna pasif dan mudah dipengaruhi oleh media massa. Oleh karena itu muncullah teori ini yang menyatakan jika pengguna media dipandang sebagai pengguna yang aktif dimana mereka menggunakan media dikarenakan kebutuhan akan informasi, komunikasi dan lain sebagainya. Teori ini menjadikan pengguna media sebagai fokus utamanya bukan kepada pemilik media. Pada awal tahun 1970-an, Schramm akhirnya meminta kepada para pengikutnya agar teori bullet tersebut dihapus dan dihilangkan, sebab pengguna media yang menjadi sasaran media massa itu ternyata tidak pasif justru sebaliknya.

Didalam teori uses and gratifications pengguna media dilihat sebagai individu aktif dan memiliki tujuan, bertanggung jawab dalam pemilihan media yang akan dengan penulisan melalui dokumentasi video yang di-upload di Instagram.

\section{Kepustakaan}

Yaitu mencari atau menggali informasi atau pengetahuan yang berhubungan dengan penulisan ini melalui sumbersumber ilmiah seperti buku-buku, jurnal dan lainnya.

digunakan untuk memenuhi kebutuhannya. Menurut teori ini, individu sadar akan kebutuhannya dan bagaimana individu memenuhi kebutuhannya sendiri. Teori uses and gratifications juga menjelaskan bahwa penggunaan media berdasarkan motif tententu. Motif merupakan sekumpulan kepentingan dari individu, oleh karena itu individu menggunakan media masa untuk memenuhi kepentingankepentingannya sendiri. Teori ini mengasumsikan pengguna media sebagai individu yang "pintar" dan aktif karena individu hanya menggunakan media yang dapat memenuhi kebutuhannya sendiri.

Pada tahun 1954 Schramm mencoba mengembangkan suatu penelitian dalam menentukan "apa yang dipilih individu atas apa yang ditawarkan media massa." Misalnya terkait dengan penelitian penulis yaitu apa yang akan dipilih individu/mad'u/follower untuk memenuhi kebutuhannya, seperti mendengrakan kajian online lewat Instagram di masa pandemi ini. Berikut rumusan yang dikemukakan Schramm: ${ }^{11}$

$$
\text { Janji Imbalan = Probabilitas Seleksi }
$$

\section{Upaya yang Diperlukan}

Scrhamm menegaskan bahwa tingkat kepuasan yang diharapkan dari media yang digunakan adalah dengan cara

${ }^{10}$ Jeffrey T. Child and Paul Haridakis, "Uses and Gratifications Theory," Engaging Theories in Family Communication (2018): 337-348. membandingkannya dengan banyak pengorbanan yang harus diberikan untuk mendapatkan hasil. Gagasan ini termasuk

11 Morissan, Teori Komunikasi Individu Hingga Massa (2nd ed). Jakarta: Kencana, (2014): 83. 
elemen utama dari teori uses and gratifications.

Dalam rangka perkembangan teori uses and gratifications dilakukan pada dekade 1960-1970-an. Pada dekade ini penelitian yang berkaitan dengan penggunaan teori ini lebih memfokuskan pada identifikasi variabel-variabel psikologis dan sosial yang diperkirakan sebagai precursors dalam perbedaan pola konsumsi media massa. Pada dasarnya uses and gratifications selalu membawa pendekatan yang mutakhir pada tahap awal setiap media komunikasi massa baru. ${ }^{12}$

Terdapat tiga karakteristik dari teori uses and gratifications dalam komunikasi berbasis online, yaitu:

1. Interactivity, bermakna suatu kondisi dimana individu dalam proses komunikasi memiliki kontrol dan dapat merubah peran dalam proses tersebut (komunikator-komunikan).

2. Demassification, adalah peluang dari individu pengguna media untuk memilih dari menu yang amat luas/bervariasi. Tidak seperti media tradisional lainnya, internet dalam hal ini mengijinkan para penggunanya untuk menyesuaikan pesan sesuai dengan kebutuhan mereka.

\section{PEMBAHASAN}

Selama kurun waktu 2019-2021 banyak aktivitas masyarakat digital berkurang akibat mewabahnya covid-19 ini. Tidak seperti biasanya bahkan hampir semua negara menerapkan lockdown atau di Indonesia dikenal dengan istilah Pemberlakuan Pembatasan Kegiatan Masyarakat (PPKM) sampai waktu yang telah ditetapkan oleh Pemerintah. Tentu masyarakat digital tidak bisa menolak dan harus melakukan aktifitas di rumah atau dikenal dengan istilah work form home.

12 Baran, S.J. \& Davis, D.K. Mass Communication Theory Foundation, Ferment and Future (5th eds). Boston: Wadsworth. (2009): 237
3. Asynchroneity, bermakna bahwa pesan yang dibawa oleh media internet dapat menghubungkan komunikator dan komunikan pada waktu yang berbeda, namun masih tetap dapat berinteraksi secara nyaman. Seorang individu dapat mengirim, menerima dan menyimpan pesan sesuai keinginannya. Untuk media online asynchroneity bermakna individu dapat menyimpan sebuah tayangan lewat laman media sosial untuk kemudian ditontonnya kembali pada waktu yang lain.

Dari ketiga karakteristik teori uses and gratifications yang digunakan dalam penelitian ini. Penulis ingin mengetahui bagaimana perspektif masyarakat digital terhadap penggunaan Instagram sebagai kebutuhan primer mereka untuk memenuhi kebutuhan dan kepuasannya dalam mencari ilmu agama di masa pandemi ini. Mewabahnya covid-19 secara global berdampak pada penggunaan internet dengan interaktivitas dan konektivitas yang tinggi yang mengakibatkan aktivitas dakwah di media sosial Instagram menjadi lebih konvergensif, menjadi lebih mudah, tak terbatas ruang dan waktu serta murah dan terbuka.

Penerapan protokol kesehatan pun diberlakukan secara ketat di berbagai tempat, sehingga kajian keagamaan yang biasa dilakukan secara normal dengan tetap muka (offline) bergeser menjadi kajian jarak jauh (online). Oleh karenanya kegiatan dakwah online di Instagram juga perlu adanya pendalaman materi keagamaan dari para da'i untuk memenuhi kebutuhan para pengunjung Instagram dalam melakukan aktifatas dirumah selama masa pandemi ini. . 
Penulis menerapakan tiga karakteristik teori uses and gratifications, yang penulis terapkan dalam penelitian ini, yaitu:

1. Interactivity, bermakna terjadi komunikasi dua arah dimana masingmasing pengguna dapat berperan sebagai pengirim dan penerima pesan dan menembus batas ruang dan waktu. Itu artinya baik da'i maupun mad'u sama-sama menjalin komunukasi dari dua arah seperti dalam percakapan tatap muka (face to face) secara online tanpa ada hambatan di laman media sosial Instagramnya.

2. Demassification, bermakna kontrol sistem komunikasi bergeser dari media massa ke pengguna media. Ini menjadi otoritas bagi mad'u atau follower sebagai pengguna Instagram untuk memilih dari menu pesan dakwah yang bervariasi yang di-upload dan diposting para da'i di laman sosial Instagramnya sesuai kebutuhannya.

3. Asynchroneity, bermakna kemampuan untuk menentukan waktu pengiriman dan penerimaan pesan pada waktu yang dikehendaki dari aspek interpersonal. Itu artinya pesan dakwah yang diupload para da'i di laman media sosial

Berikut adalah klasifikasi para da'i yang penulis batasi dari 8,8 juta follower sampai 1,7 juta follower dan respon dari beberapa follower yang dikaji menggunakan teori uses and gratification, sebagai berikut:

1. Ustadz Hanan Attaki, Lc (8,8 juta follower)

2. Ustadz Abdullah Gymnastiar / Aa Gym (6,7 juta follower)

3. Ustadz Abdul Somad, Lc. MA., Ph.D. (5,6 juta follower $)$

4. Ustadz Felix Siauw (4,8 juta follower)

5. Buya Yahya (3,7 juta follower)

6. Ustadz Adi Hidayat, Lc, MA (3,2 juta follower)

7. Ustadz Dr. Khalid Basalamah, Lc, MA (2,5 juta follower)
Instagramnya dapat menghubungkan da'i dan mad'u atau follower pada waktu yang sama ataupun berbeda tergantung pada kebutuhannya. Namun mereka masih tetap dapat berinteraksi secara interpersonal.

Dari ketiga karakteristik diatas membuktikan bahwa dakwah online melalui Instagram telah menjadikan agama dan spiritualitas umumnya tampil sebagai kebutuhan mendasar khususnya bagi masyarakat digital. Penulis melihat bagaimana aktifitas masyarakat digital konsisten mengikuti kajian dakwah online di laman media sosial Instagram para da'i. Sehingga dapat dikatakan mereka mampu memanfaatkan media sosial Instagram sebagai wadah untuk terus belajar agama dimasa pandemi ini. Seperti mengikuti kajian ustadz Hanan Attaki, ustadz Abdul Somad, ustadz Khalid Basalamah, ustadz Adi Hidayat, dan ustadz-ustadz lainya dengan materi dakwah yang mudah dipahami dengan bahasa yang santun dan lembut. Ini menjadi bukti kongkrit eksistensi para da'i dalam menyebarkan risalah agama Islam yang mudah diterima secara masal dengan semakin bertambahnya jumlah follower mereka.

8. Ustadz Dr. Syafiq Riza Basalamah, Lc, MA (1,7 juta follower 
Tabel 1. Klasifikasi Da'i dan Respon Follower

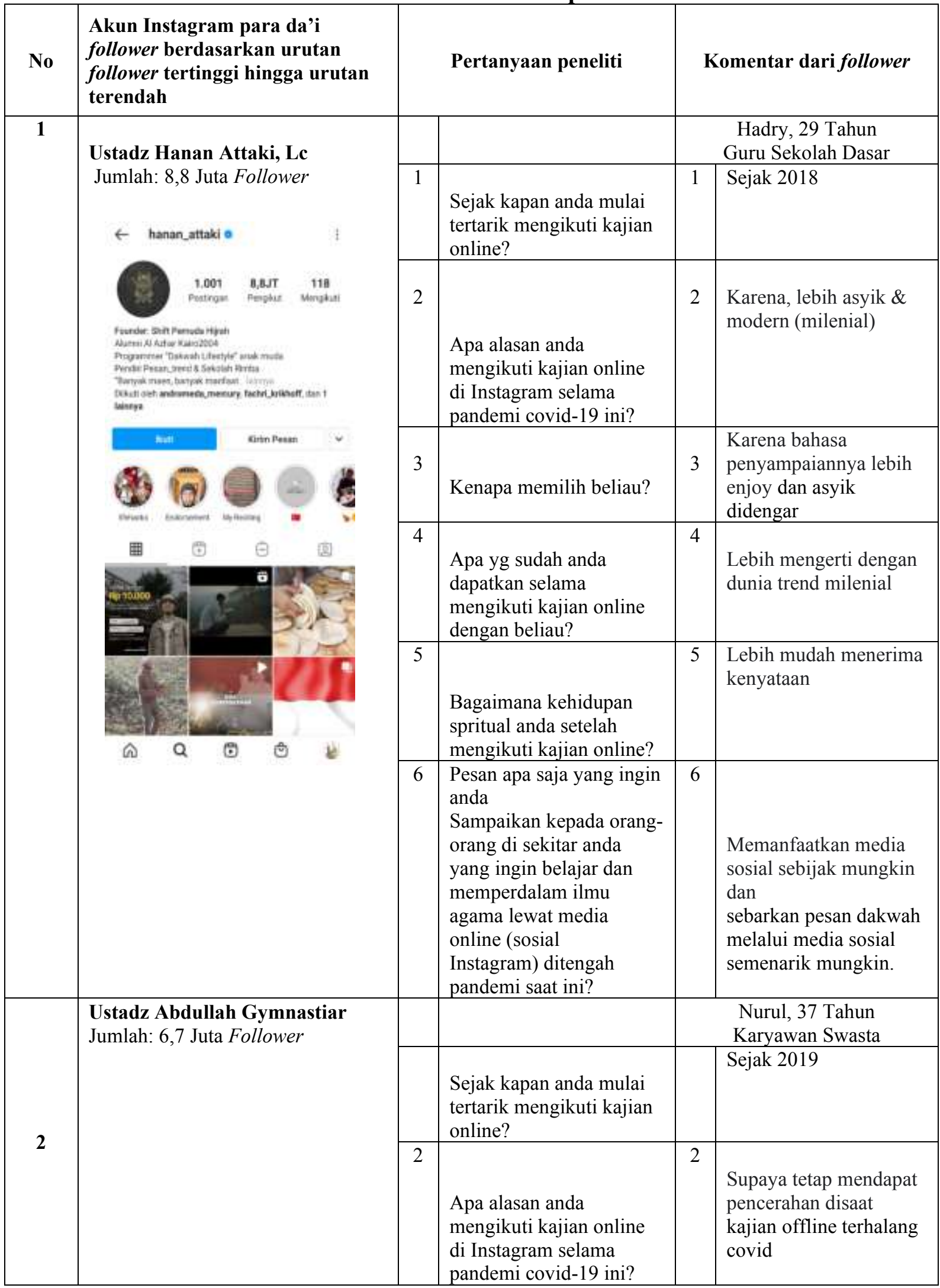




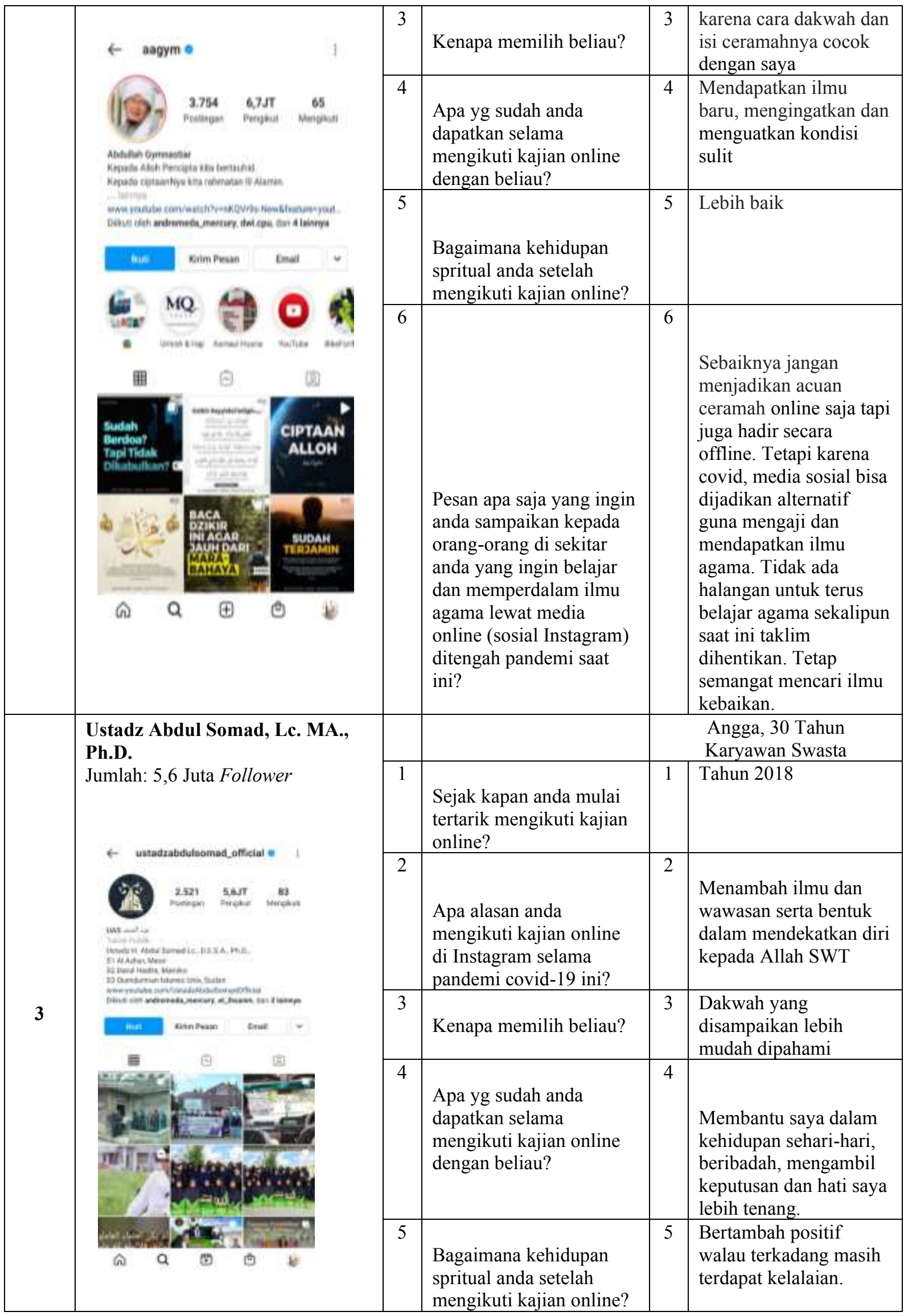




\begin{tabular}{|c|c|c|c|c|c|}
\hline & & 6 & $\begin{array}{l}\text { Pesan apa saja yang ingin } \\
\text { anda sampaikan kepada } \\
\text { orang-orang di sekitar } \\
\text { anda yang ingin belajar } \\
\text { dan memperdalam ilmu } \\
\text { agama lewat media } \\
\text { online (sosial Instagram) } \\
\text { ditengah pandemi saat } \\
\text { ini? }\end{array}$ & 6 & $\begin{array}{l}\text { Hanya Allah SWT lah } \\
\text { yang pantas } \\
\text { menentukan mana yang } \\
\text { benar dan mana yang } \\
\text { salah }\end{array}$ \\
\hline \multirow{7}{*}{4} & $\begin{array}{l}\text { Ustadz Felix Siauw } \\
\text { Jumlah: } 4,8 \text { Juta Follower }\end{array}$ & & & \multicolumn{2}{|r|}{$\begin{array}{c}\text { Deni, } 37 \text { Tahun } \\
\text { Mahasiswa UIN Jakarta }\end{array}$} \\
\hline & \multirow{6}{*}{ 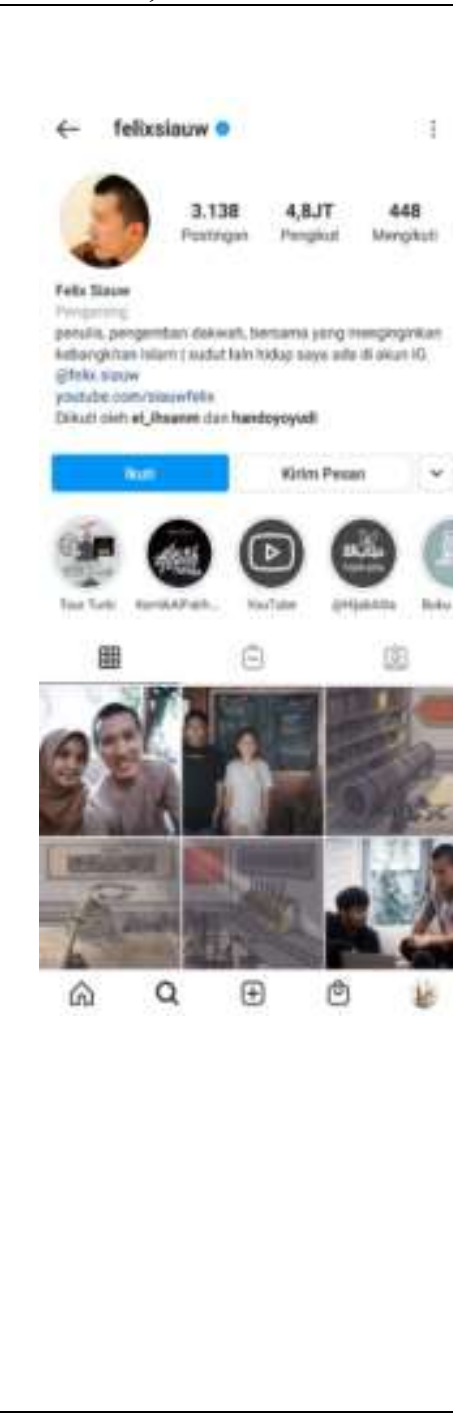 } & & $\begin{array}{l}\text { Sejak kapan anda mulai } \\
\text { tertarik mengikuti kajian } \\
\text { online? }\end{array}$ & & $\begin{array}{l}\text { Sejak muncul di } \\
\text { Instagram }\end{array}$ \\
\hline & & 2 & $\begin{array}{l}\text { Apa alasan anda } \\
\text { mengikuti kajian online } \\
\text { di Instagram selama } \\
\text { pandemi covid-19 ini? }\end{array}$ & 2 & $\begin{array}{l}\text { Karena itu merupakan } \\
\text { salah satu alternative } \\
\text { kita sebagai umat } \\
\text { muslim. untuk terus } \\
\text { memupuk ilmu } \\
\text { keagamaan ditengah } \\
\text { keterbatasan }\end{array}$ \\
\hline & & 3 & Kenapa memilih beliau? & 3 & $\begin{array}{l}\text { Membantah argumen } \\
\text { lawan debat dengan } \\
\text { ilmiah }\end{array}$ \\
\hline & & 4 & $\begin{array}{l}\text { Apa yg sudah anda } \\
\text { dapatkan selama } \\
\text { mengikuti kajian online } \\
\text { dengan beliau? }\end{array}$ & 4 & Wawasan sejarah Islam \\
\hline & & 5 & $\begin{array}{l}\text { Bagaimana kehidupan } \\
\text { spritual anda setelah } \\
\text { mengikuti kajian online? }\end{array}$ & 5 & $\begin{array}{l}\text { Menambah wawasan ke } \\
\text { Islaman }\end{array}$ \\
\hline & & 6 & $\begin{array}{l}\text { Pesan apa saja yang ingin } \\
\text { anda sampaikan kepada } \\
\text { orang-orang di sekitar } \\
\text { anda yang ingin belajar } \\
\text { dan memperdalam ilmu } \\
\text { agama lewat media } \\
\text { online (sosial Instagram) } \\
\text { ditengah pandemi saat } \\
\text { ini? }\end{array}$ & 6 & $\begin{array}{l}\text { Manfaatkan Instagram } \\
\text { atau media sosial } \\
\text { lainnya untuk } \\
\text { menambah wawasan } \\
\text { keislaman sehingga } \\
\text { ilmu dan pengetahuan } \\
\text { bertambah dan menjadi } \\
\text { pribadi yang lebih baik } \\
\text { lagi. }\end{array}$ \\
\hline \multirow{3}{*}{5} & $\begin{array}{l}\text { Buya Yahya } \\
\text { Jumlah: } 3,7 \text { Juta Follower }\end{array}$ & & & \multicolumn{2}{|r|}{$\begin{array}{c}\text { Misbah, } 26 \text { Tahun Ponpes } \\
\text { As-Sidiqiyah }\end{array}$} \\
\hline & & 1 & $\begin{array}{l}\text { Sejak kapan anda mulai } \\
\text { tertarik mengikuti kajian } \\
\text { online? }\end{array}$ & 1 & Sejak 2021 \\
\hline & & 2 & $\begin{array}{l}\text { Apa alasan anda } \\
\text { mengikuti kajian online }\end{array}$ & 2 & $\begin{array}{l}\text { Lebih mudah dan } \\
\text { praktis }\end{array}$ \\
\hline
\end{tabular}




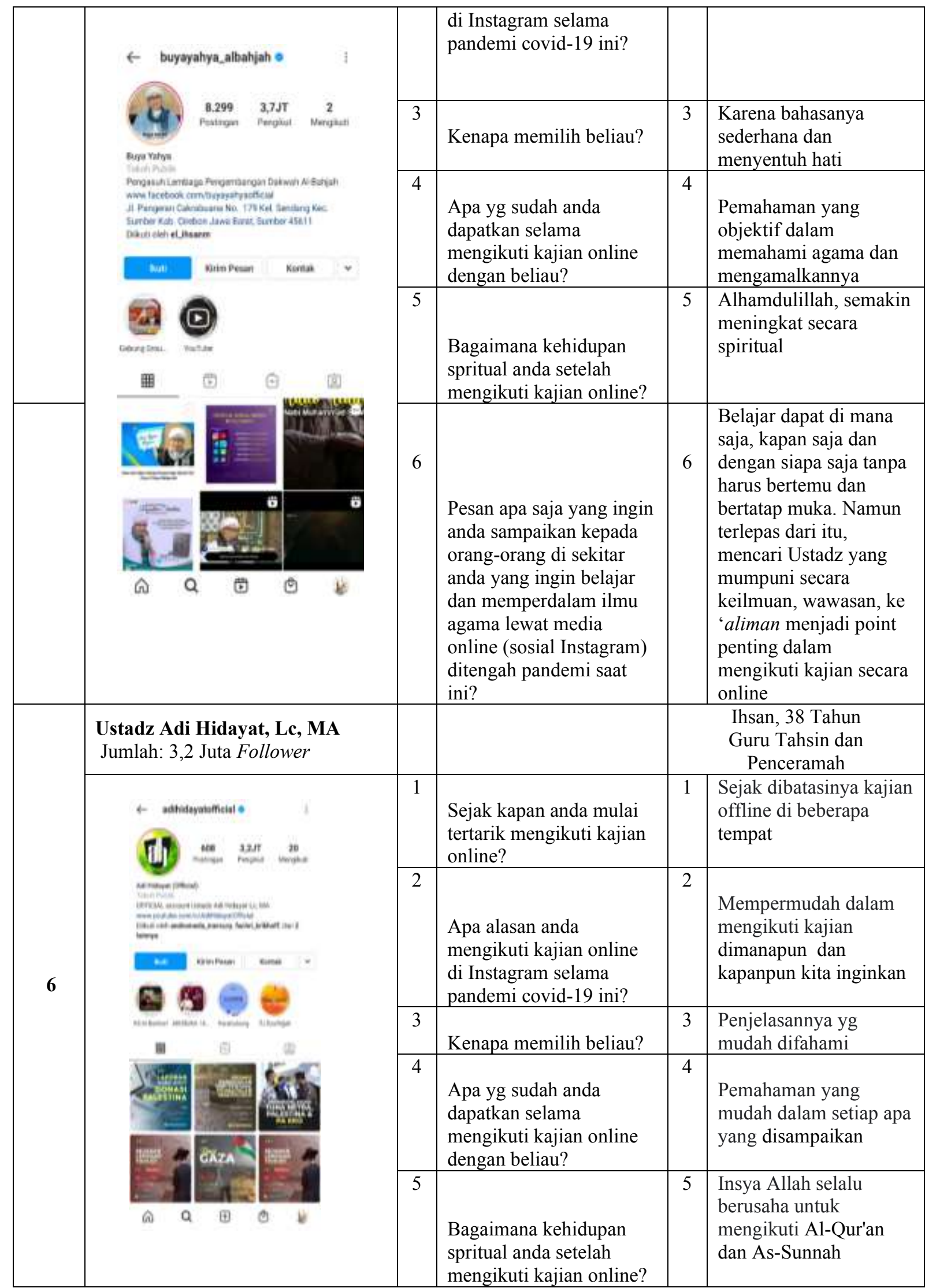




\begin{tabular}{|c|c|c|c|c|c|}
\hline & & 6 & $\begin{array}{l}\text { Pesan apa saja yang ingin } \\
\text { anda sampaikan kepada } \\
\text { orang-orang di sekitar } \\
\text { anda yang ingin belajar } \\
\text { dan memperdalam ilmu } \\
\text { agama lewat media } \\
\text { online (sosial Instagram) } \\
\text { ditengah pandemi saat } \\
\text { ini? }\end{array}$ & 6 & $\begin{array}{l}\text { Berusaha } \\
\text { menyempatkan waktu } \\
\text { untuk selalu bisa } \\
\text { mengikuti kajian } \\
\text { kapanpun }\end{array}$ \\
\hline \multirow{4}{*}{7} & $\begin{array}{l}\text { Ustadz Dr. Khalid Basalamah, } \\
\text { Lc, MA } \\
\text { Jumlah: 2,5 Juta Follower }\end{array}$ & & & \multicolumn{2}{|r|}{$\begin{array}{l}\text { Zulham, } 38 \text { Tahun } \\
\text { Karyawan Swasta }\end{array}$} \\
\hline & \multirow[b]{2}{*}{ 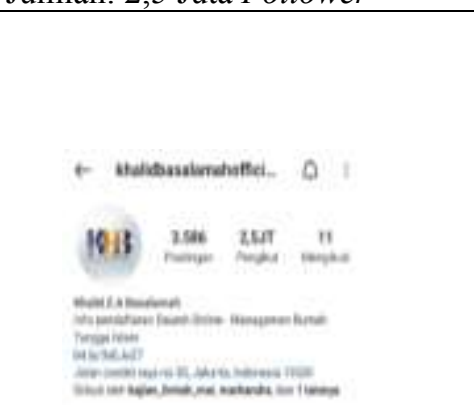 } & 1 & $\begin{array}{l}\text { Sejak kapan anda mulai } \\
\text { tertarik mengikuti kajian } \\
\text { online? }\end{array}$ & 1 & Sejak 2016 kurang lebih \\
\hline & & 2 & $\begin{array}{l}\text { Apa alasan anda } \\
\text { mengikuti kajian online } \\
\text { di Instagram selama } \\
\text { pandemi covid-19 ini? }\end{array}$ & 2 & $\begin{array}{l}\text { Menambah ilmu agama } \\
\text { bisa menambah iman, } \\
\text { jadi makin sabar dan } \\
\text { bersyukur menyikapi } \\
\text { segala masalah. }\end{array}$ \\
\hline & 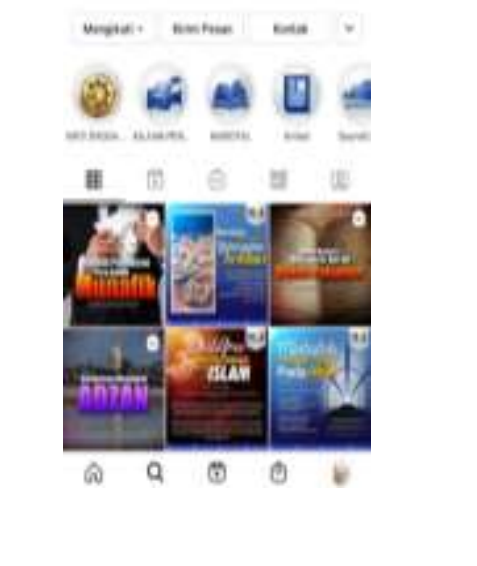 & 3 & Kenapa memilih beliau? & 3 & $\begin{array}{l}\text { Karena saya mencintai } \\
\text { beliau karena Allah } \\
\text { SWT, beliau } \\
\text { menyampaikan ilmu } \\
\text { dengan berpegang } \\
\text { teguh terhadap Al- } \\
\text { Qur'an dan hadits } \\
\text { dengan pemahaman } \\
\text { generasi terbaik umat } \\
\text { Islam yaitu generasinya } \\
\text { para sahabat Nabi } \\
\text { Muhammad SAW. }\end{array}$ \\
\hline & & 4 & $\begin{array}{l}\text { Apa yg sudah anda } \\
\text { dapatkan selama } \\
\text { mengikuti kajian online } \\
\text { dengan beliau? }\end{array}$ & 4 & $\begin{array}{l}\text { Alhamdulillah saya } \\
\text { mendapatkan ilmu yang } \\
\text { membuat saya paham } \\
\text { karena sejatinya dunia } \\
\text { ini adalah jalan menuju } \\
\text { akhirat. Sadar akan } \\
\text { kematian yang pasti } \\
\text { datangnya. Sadar akan } \\
\text { pertanggung jawaban } \\
\text { yang berat di hari akhir } \\
\text { kelak. }\end{array}$ \\
\hline & & 5 & $\begin{array}{l}\text { Bagaimana kehidupan } \\
\text { spritual anda setelah } \\
\text { mengikuti kajian online? }\end{array}$ & 5 & $\begin{array}{l}\text { Tentunya saya semakin } \\
\text { berhati hati melakukan } \\
\text { dosa, karena rasa takut } \\
\text { saya terhadap siksa } \\
\text { Allah SWT, terlebih } \\
\text { dosa saya yang sudah } \\
\text { terlalu banyak membuat }\end{array}$ \\
\hline
\end{tabular}




\begin{tabular}{|c|c|c|c|c|c|}
\hline & & & & & $\begin{array}{l}\text { saya selalu berusaha } \\
\text { bertaubat setiap harinya }\end{array}$ \\
\hline & & 6 & $\begin{array}{l}\text { Pesan apa saja yang ingin } \\
\text { anda sampaikan kepada } \\
\text { orang-orang di sekitar } \\
\text { anda yang ingin belajar } \\
\text { dan memperdalam ilmu } \\
\text { agama lewat media } \\
\text { online (sosial Instagram) } \\
\text { ditengah pandemi saat } \\
\text { ini? }\end{array}$ & 6 & $\begin{array}{l}\text { Bagi saya ilmu bisa kita } \\
\text { dapatkan lewat kajian } \\
\text { di Instagram, yang } \\
\text { terpenting luruskan hati } \\
\text { dan luruskan niat agar } \\
\text { Allah SWT selalu } \\
\text { bimbing kita ke jalan } \\
\text { kebenaran, jalan yang } \\
\text { lurus. Dari niat tersebut } \\
\text { insya Allah kita bisa } \\
\text { dapat menemukan } \\
\text { hidayah, menemukan } \\
\text { siapa guru yang bisa } \\
\text { kita ambil ilmunya } \\
\text { lewat Instagram. }\end{array}$ \\
\hline \multirow{7}{*}{8} & \multirow{7}{*}{$\begin{array}{l}\text { Ustadz Dr. Syafiq Riza } \\
\text { Basalamah, Lc, MA } \\
\text { Jumlah: 1,7 Juta Follower }\end{array}$} & & & \multicolumn{2}{|c|}{$\begin{array}{c}\text { Arief, } 38 \text { Tahun Karyawan } \\
\text { Swasta }\end{array}$} \\
\hline & & 1 & $\begin{array}{l}\text { Sejak kapan anda mulai } \\
\text { tertarik mengikuti kajian } \\
\text { online? }\end{array}$ & 1 & Sejak 2013 \\
\hline & & 2 & $\begin{array}{l}\text { Apa alasan anda } \\
\text { mengikuti kajian online } \\
\text { di Instagram selama } \\
\text { pandemi covid-19 ini? }\end{array}$ & 2 & $\begin{array}{l}\text { Karena dilarangnya } \\
\text { kajian offline, maka } \\
\text { untuk terus } \\
\text { mendapatkan ilmu } \\
\text { maka saya harus tetap } \\
\text { belajar meskipun online }\end{array}$ \\
\hline & & 3 & Kenapa memilih beliau? & 3 & $\begin{array}{l}\text { Karena sesuai dengan } \\
\text { manhaj yang saya } \\
\text { yakini }\end{array}$ \\
\hline & & 4 & $\begin{array}{l}\text { Apa yg sudah anda } \\
\text { dapatkan selama } \\
\text { mengikuti kajian online } \\
\text { dengan beliau? }\end{array}$ & 4 & Ilmu yang bermanfaat \\
\hline & & 5 & $\begin{array}{l}\text { Bagaimana kehidupan } \\
\text { spritual anda setelah } \\
\text { mengikuti kajian online? }\end{array}$ & 5 & Lebih baik \\
\hline & & 6 & $\begin{array}{l}\text { Pesan apa saja yang ingin } \\
\text { anda sampaikan kepada } \\
\text { orang-orang di sekitar } \\
\text { anda yang ingin belajar } \\
\text { dan memperdalam ilmu } \\
\text { agama lewat media } \\
\text { online (sosial Instagram) } \\
\text { ditengah pandemi saat } \\
\text { ini? }\end{array}$ & 6 & $\begin{array}{l}\text { Cari ustadz yang sesuai } \\
\text { dengan manhaj diyakini } \\
\text { benar jangan } \\
\text { membenturkan ustadz- } \\
\text { ustadz media sosial } \\
\text { ketika berbeda pendapat }\end{array}$ \\
\hline
\end{tabular}




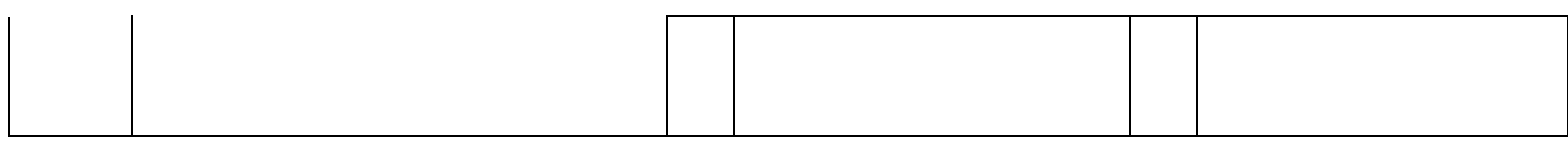

Tabel 2. Follower dalam Teori Uses and Gratifications

\begin{tabular}{|c|c|c|c|c|}
\hline \multirow{2}{*}{ NO } & \multirow{2}{*}{ Follower } & \multicolumn{3}{|c|}{ TEORI USES AND GRATIFICATION } \\
\hline & & Interactivity & Demassification & Asynchroneity \\
\hline 1 & $\begin{array}{l}\text { Hadry follower } \\
\text { Ustadz Hanan } \\
\text { Attaki, LC }\end{array}$ & $\begin{array}{l}\text { Proses } \\
\text { komunukasi dua } \\
\text { arah antara da;i } \\
\text { dan } \\
\text { mad'u/follower } \\
\text { lewat Instagram. }\end{array}$ & $\begin{array}{l}\text { Menu kajian online } \\
\text { yang menjadi daya } \\
\text { tarik bagi } \\
\text { mad'u/follower } \\
\text { mengikuti kajian ini } \\
\text { adalah mengenal } \\
\text { dunia trend milenial }\end{array}$ & $\begin{array}{l}\text { Feedback dari pesan } \\
\text { dakwah yang diterima } \\
\text { mad'u/follower pada } \\
\text { kajian online ini } \\
\text { adalah lebih mudah } \\
\text { menerima kenyataan } \\
\text { hidup. }\end{array}$ \\
\hline 2 & $\begin{array}{l}\text { Nurul follower } \\
\text { Ustadz Abdullah } \\
\text { Gymnastiar / Aa } \\
\text { Gym }\end{array}$ & $\begin{array}{l}\text { Proses } \\
\text { komunukasi dua } \\
\text { arah antara da;i } \\
\text { dan } \\
\text { mad'u/follower } \\
\text { lewat Instagram. }\end{array}$ & $\begin{array}{l}\text { Menu kajian online } \\
\text { yang menjadi daya } \\
\text { tarik bagi } \\
\text { mad'u/follower } \\
\text { mengikuti kajian ini } \\
\text { adalah adalah solusi } \\
\text { kehidupan dimasa } \\
\text { pandemi. }\end{array}$ & $\begin{array}{l}\text { Feedback dari pesan } \\
\text { dakwah yang diterima } \\
\text { mad'u/follower pada } \\
\text { kajian online ini } \\
\text { adalah menjadi } \\
\text { pribadi yang lebih } \\
\text { baik. }\end{array}$ \\
\hline 3 & $\begin{array}{l}\text { Angga follower } \\
\text { Ustadz Abdul } \\
\text { Somad, Lc. MA., } \\
\text { Ph.D }\end{array}$ & $\begin{array}{l}\text { Proses } \\
\text { komunukasi dua } \\
\text { arah antara da;i } \\
\text { dan } \\
\text { mad'u/follower } \\
\text { lewat Instagram. }\end{array}$ & $\begin{array}{l}\text { Menu kajian online } \\
\text { yang menjadi daya } \\
\text { tarik bagi } \\
\text { mad'u/follower } \\
\text { mengikuti kajian ini } \\
\text { adalah cara } \\
\text { beribadah kepada } \\
\text { Allah SWT. }\end{array}$ & $\begin{array}{l}\text { Feedback dari pesan } \\
\text { dakwah yang diterima } \\
\text { mad'u/follower pada } \\
\text { kajian online ini } \\
\text { adalah meningkatkan } \\
\text { kualitas ibadah dan } \\
\text { tepat mengambil } \\
\text { keputusan. }\end{array}$ \\
\hline 4 & $\begin{array}{l}\text { Deni follower } \\
\text { Ustadz Felix } \\
\text { Siauw }\end{array}$ & $\begin{array}{l}\text { Proses } \\
\text { komunukasi dua } \\
\text { arah antara da;i } \\
\text { dan } \\
\text { mad'u/follower } \\
\text { lewat Instagram. }\end{array}$ & $\begin{array}{l}\text { Menu kajian online } \\
\text { yang menjadi daya } \\
\text { tarik bagi } \\
\text { mad'u/follower } \\
\text { mengikuti kajian ini } \\
\text { adalah sejarah Islam }\end{array}$ & $\begin{array}{l}\text { Feedback dari pesan } \\
\text { dakwah yang diterima } \\
\text { mad'u/follower pada } \\
\text { kajian online ini } \\
\text { adalah menambah } \\
\text { wawasan ke Islaman. }\end{array}$ \\
\hline 5 & $\begin{array}{l}\text { Misbah follower } \\
\text { Buya Yahya }\end{array}$ & $\begin{array}{l}\text { Proses } \\
\text { komunukasi dua } \\
\text { arah antara da;i } \\
\text { dan } \\
\text { mad'u/follower } \\
\text { lewat Instagram. }\end{array}$ & $\begin{array}{l}\text { Menu kajian online } \\
\text { yang menjadi daya } \\
\text { tarik bagi } \\
\text { mad'u/follower } \\
\text { mengikuti kajian ini } \\
\text { adalah ilmu agama } \\
\text { dan cara } \\
\text { mengamalkannya }\end{array}$ & $\begin{array}{l}\text { Feedback dari pesan } \\
\text { dakwah yang diterima } \\
\text { mad'u/follower pada } \\
\text { kajian online ini } \\
\text { adalah menjadi } \\
\text { pribadi yang lebik } \\
\text { baik lagi }\end{array}$ \\
\hline
\end{tabular}




\begin{tabular}{|c|l|l|l|l|}
\hline \multirow{6}{*}{6} & $\begin{array}{l}\text { Ihsan follower } \\
\text { Ustadz Adi } \\
\text { Hidayat, Lc, MA } \\
\text { Proses } \\
\text { komunukasi dua } \\
\text { arah antara da;i } \\
\text { dan } \\
\text { mad'u/follower } \\
\text { lewat Instagram. }\end{array}$ & $\begin{array}{l}\text { Menu kajian online } \\
\text { yang menjadi daya } \\
\text { tarik bagi } \\
\text { mad'u/follower } \\
\text { adalah mengikuti } \\
\text { kajian ini adalah } \\
\text { ilmu agama yang } \\
\text { mudah dipahami }\end{array}$ & $\begin{array}{l}\text { Feedback dari pesan } \\
\text { dakwah yang diterima } \\
\text { mad'u/follower pada } \\
\text { kajian online ini } \\
\text { adalah berusaha untuk } \\
\text { mengikuti Al-Qur'an } \\
\text { dan As-Sunnah }\end{array}$ \\
\hline 8 & $\begin{array}{l}\text { Arief follower } \\
\text { Riza Basalamah, } \\
\text { Lc, MA }\end{array}$ & $\begin{array}{l}\text { Proses } \\
\text { komunukasi dua } \\
\text { arah antara da;i } \\
\text { dan } \\
\text { mad'u/follower } \\
\text { lewat Instagram }\end{array}$ & $\begin{array}{l}\text { yang menjadi daya } \\
\text { tarik bagi } \\
\text { mad'u/follower } \\
\text { mengikuti kajian ini } \\
\text { adalah Ilmu agama } \\
\text { yang bermanfaat }\end{array}$ & $\begin{array}{l}\text { Feedback dari pesan } \\
\text { dakwah yang diterima } \\
\text { mad'u/follower pada } \\
\text { kajian online ini } \\
\text { adalah mengikuti } \\
\text { manhaj yang lurus. }\end{array}$ \\
\hline
\end{tabular}

Dari pemaparan tabel diatas, penulis akan mengulas satu persatu aktifitas dakwah online para da'i berdasarkan 1. Ustadz Hanan Attaki dengan 8,8 juta follower, melampaui jumlah follower dari ketujuh da'i lainnya, dengan konsep dakwah lifestyle dan trend milenialnya ternyata banyak diminati dan menjadi daya tarik tersendiri bagi para pengunjung Instagramnya. Isi dakwahnya banyak memberikan inspirasi dan memotivasi kaum melienial, seperti: sabar dalam menghadapi cobaan hidup diera pandemi, jangan bersedih dan berkecil hati, membangun ekonomi kreatif, anjuran bersedekah dan lain sebagainya. Tema-tema tersebut dikemas dengan menarik dan banyak mengundang ribuan komentar positif yang mengisi kolom komentar dilaman Instagramnya. Gayanya yang nyentrik dan gaul mampu menarik calon muda-mudi yang ingin hijrah dan mendalami ilmu agama sesuai Al-Qur'an dan Sunnah. ${ }^{13}$

2. Ustadz Abdullah Gymnastiar atau dikenal dengan nama Aa Gym dengan 6,7 juta follower. Dikanal dengan tagline siraman qalbu, penyampaian

\footnotetext{
${ }^{13} \mathrm{https}: / /$ www.instagram.com/hanan_attaki/

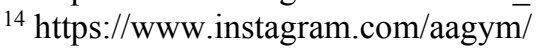

interactivity, demassification, dan asynchroneity dari teori uses and gratification, diantaranya:

dakwahnya yang begitu lembut dan menyentuh hati, banyak bercerita tentang pentingnya menjaga hati agar tidak dikotori dengan sifat iri hati dan dengki sesama manusia sehingga mudah diterima para pengunjung Instagramnya terutama bagi kaum "ibuibu" sebagai obat hati untuk menyelesaikan permasalahan hidup ${ }^{14}$

3. Ustadz Abdul Somad dengan 5,6 juta follower, da'i yang biasa dipanggil dengan nama UAS ini banyak mengulas berbagai masalah dan persoalan hidup. Seperti meningkatkan kualitas ibadah dan banyak bersedekah dijalan Allah Subhanahu Wata'ala. Sehingga menginspirasi para pengunjung Instagramnya untuk terus berbagi memberikan sebagian hartanya dijalan yang diridhoi-Nya. ${ }^{15}$

4. Ustadz Felix Siauw dengan 4,8 juta follower, banyak membahas tentang sejarah Islam sehingga menginspirasi para pengunjung Instagramnya untuk

15

https://www.instagram.com/ustadzabdulsomad_off icial/ 
mengenal lebih banyak tentang sejarah Islam. $^{16}$

5. Buya Yahya dengan 3,7 juta follower, da'i dengan nama asli Yahya Zainul Ma'arif ini banyak membahas ilmu fiqh, ilmu tafsir, tasawuf, dan manfaat bersedekah dan lain sebagainya sehingga menginspirasi para pengunjung Instagramnya untuk menjadi pribadi yang lebih baik lagi. ${ }^{17}$

6. Ustadz Adi Hidayat dengan 3,2 juta follower, banyak membahas kitab tafisr Al-Qura'an dan Hadits sehingga memudahkan para pengunjung Instagramnya untuk memahami isi kandungan ayat-ayat Al-Qur'an dan Hadist sesuai sanad dan matannya. ${ }^{18}$

7. Ustadz Khalid Basalamah dengan 2,5 juta follower, pemilik Gazwah TV Dari pemaparan diatas, terlihat interactivity, demassification, dan asynchroneity yang saling berkesinambungan antara da'i dan mad'u (follower) dan berperan aktif dalam pengguna media sosial Instagram pada kegiatan dakwah online ditengah pandemi ini. Hal ini selaras dengan apa yang dikemukakan Wilbur Schramm dalam teori

\section{KESIMPULAN}

Aktifitas dakwah online ditengah pandemi covid-19 menjadi kesempatan para da'i untuk memperluas cakrawala dakwahnya dengan melebarkan sayapnya keberbagai penjuru dunia. Kesempatan yang dimaksud ialah bagaimana para da'i mampu menguasai dan memanfaatkan dengan sebaik-baiknya perkembangan teknologi internet dan komunikasi visual di laman media sosial Instagramnya dengan cara interactivity, demassification, dan asynchroneity. Sehingga terjalin komunikasi yang baik antara da'i dan

\footnotetext{
${ }^{16} \mathrm{https}: / / \mathrm{www}$. instagram.com/felixsiauw/

17 https://www.instagram.com/buyayahya albahjah/$$
18
$$

https:/www.instagram.com/adihidayatofficial/
}

dibilangan Condet Jakarta Timur ini banyak membahas kitab tauhid untuk kembali kepada Al-Qur'an dan Sunnah, rahasia rezeki, persoalan rumah tangga, kehidupan akhirat dan lain sebagainya sehingga menginspirasi para pengunjung Instagramnya untuk berhati-hati dalam berbuat agar terhindar dari dosa. ${ }^{19}$

8. Ustadz Syafiq Riza Basalamah dengan 1,7 juta follower, banyak membahas kitab tauhid untuk kembali kepada AlQur'an dan Sunnah, fiqh, berbakti kepada kedua orang tua dan lain sebagainya sehingga menginspirasi para pengunjung Instagramnya untuk istiqomah berada di jalan Allah Subhanahu Wata'la. ${ }^{20}$

uses and gratifications yang menjelasakan bahwa masyarakat digital dipandang sebagai individu yang aktif dan memiliki tujuan untuk memenuhi kebutuhan dan kepuasan mereka dalam berdakwah serta memahami agama lewat media sosial Instagramnya.

mad'u (follewer) yang sama-sama memanfaatkan tekonlogi internet di media sosial Instagram mereka.

Interactivity yang dilakukan kedua belah pihak baik da'i maupun mad'u samasama menjalin komunikasi online seolaholah sedang bertatap muka sehingga kegiatan dakwah online terasa lebih dekat nyaman dan ekslusif dimata mad'u. Asynchroneity menu materi dakwah yang disampaikan da'i berkaitan dengan agama dan kehidapan sosial dan lainnya dapat dimanfaatkan mad'u untuk memilih menu

\footnotetext{
19 https://www.instagram.com/khalidbasalamah official/

https://www.instagram.com/syafiqrizabasalamah official/
} 
materi dakwah yang sudah di upload dan di posting para da'i di laman Instagramnya baik secara langsung maupun tidak langsung. Asynchroneity baik da'i maupun mad'u sama-sama aktif menjalin komunikasi interpersonal dan tidak terikat waku dan bisa kapan saja dan dimana saja bisa dilakukan.

Pemanfaatan aplikasi Instagram baik da'i maupun mad'u sama-sama saling menguntungkan kedua belah pihak. Seorang da'i dengan mudah menyebar luas kan pesan dakwahnya setelah mengupload dan men-share videonya di akun Instagramnya dan seorang mad'u atau follower tidak perlu repot-repot dan bersusah payah mengunjungi lokasi dakwah secara tatap muka (offline). Mereka bisa langsung mengikuti kajian online kapanpun dan dimanapun mereka berada sesuai keinginannya bahkan secara live streaming. Ilmu-ilmu yang didapatkanya pun tidak jauh berbada seperti mengikuti kajian offline. Terbukti dari beberapa pernyataan follower diatas bahwa covid-19 bukan sebuah hambatan dan penghalang untuk tetap aktif dan terus belajar menimba ilmu agama untuk menjadi pribadi yang lebih baik lagi dan bisa memberikan manfaat untuk orang lain.

Para da'i terus menebar kebaikan dengan khazanah ilmu agama yang luas bersumber dari Al-Qur'an dan Al-Hadits seperti apa yang diajarkan Nabi Muhammad Shollallahu A'laihi Wasallam sehingga dapat dipertanggung jawabkan. Sebab dimasa pandemi sebagaimana yang terjadi sekarang, dakwah memiliki peran penting untuk menghimbau masyarakat sebagai upaya mengambil langkah yang tepat dalam menghadapi dan menghindari penyebaran covid-19 itu sendiri. Terlebih kegiatan keagamaan diberbagai tempat masih ditutup sementara oleh pemerintah guna menekan laju penyebaran covid-19 yang masih tinggi.

Memahami agama dan menjalankannya menjadi kewajiban setiap muslim hingga akhir hayat sehingga tidak ada alasan untuk berhenti menuntut ilmu sekalipun melalui aplikasi Instagram. Dengan memahami fenomena tersebut, maka keberadaan Instagram sebagai media dakwah online telah menjadi sebuah kebutuhan dan kepuasan (uses and gratifications) bagi masyarakat digital.

\section{DAFTAR PUSTAKA}

Arifin, H. M. Psikologi Dakwah Suatu Pengantar (Cetakan Pertama). Jakarta: Bumi Aksara, 1991.

Atmoko, Dwi Bambang, Instagram Handbook, Jakarta: Media Kita, (2012)

Child, Jeffrey T., and Paul Haridakis. "Uses and Gratifications Theory." Engaging Theories in Family Communication (2018): 337-348.

Cresswell, John, Penulisan kualitatif dan desain riset: Memilih di antara 5 Pendekatan. Yogyakarta: Pustaka Pelajar. (2015): 205.

Dakwah, Strategi, Akun Penuntutilmu, F Ar Rayyan, and Universitas Ibn Khaldun. "Dawatuna: Journal of
Communication and Islamic Broadcasting Peran Instagram Sebagai Media Dakwah Pada Masa Pandemi :" 2 (2022): 81-97.

Moleong, Lexy J, Metode Penulisan Kualitatif, Bandung: Remaja Karya, (1989)

Morissan, Teori Komunikasi Individu Hingga Massa (2nd ed). Jakarta: Kencana, (2014).

Mulyana, Deddy, Analisis Framing. Jogjakarta: LKiS. (2002). 71

Pratopo, Wahyudi Marhaen, and Nasrullah Kusajibrata. "Konvergensi Di Ruang Redaksi Pada Kelompok Media Tempo." Jurnal Studi Komunikasi 
(Indonesian Journal of Communications Studies) 2, no. 1 (2018): 126-142.

S.J. Baran, \& D.K. Davis, Mass

Communication Theory

Foundation, Ferment and Future

(5th eds). Boston: Wadsworth. (2009).

Usman, Fadly. "Efektivitas Penggunaan Media Online Sebagai Sarana Dakwah." Jurnal Ekonomi dan Dakwah Islam (Al-Tsiqoh) 1, no. 1 (2016): 1-8.

Yin, Robert K Qualitative Research from Start to Finish. The Guilford: New York London (2011).

https://www.beritasatu.com/digital/733

355/data-ini-media-sosial-palingpopuler-di-indonesia-20202021

https://www.liputan6.com/tekno/read/2 504962/kisah-inspiratifperjalanan-logo-instagram

https:/www.instagram.com/hanan atta ki/

https://www.instagram.com/aagym/

https://www.instagram.com/ustadzabdu lsomad official/

https://www.instagram.com/felixsiauw/ https://www.instagram.com/buyayahya albahjah/

https://www.instagram.com/adihidayat official/

https://www.instagram.com/khalidbasal amahofficial/

https://www.instagram.com/syafiqrizab asalamah official/ 